\title{
The real smart grid for water: ensuring water sustainability via infrastructure and information
}

\author{
G. Symmonds \\ CTO, Global Water Resources, USA
}

\begin{abstract}
Water scarcity and variability are increasing worldwide. Once isolated to developing nations, water scarcity is dramatically affecting first world nations like Australia, Spain, and the United States. All nations are now recognizing that the world's water is a finite resource, and that resource is being drastically altered in both availability and quality by development, climate change and population growth. To survive in this new reality, water managers must not only increase the availability of conservation infrastructure - dual water mains, etc. they must also increase the availability of information available to consumers. Addressing this water crisis requires a fundamental change in the planning and infrastructure deployment employed for water resources; a change from the largesse policies of the past to stewardship of the future and a commitment to engage the consumer in active conservation.
\end{abstract}

Keywords: dual reticulation, smart grid for water, consumer information, water scarcity.

\section{Introduction}

"A key to improving efficiency is understanding where, when, and why we use water" [1].

Water scarcity is a looming problem and coming to grips with this as water managers is critical to achieving sustainability. The reality is that mankind has rarely - if ever - lived in complete harmony with our most necessary resource. We have relied on massive engineering works and the relative resilience of the resource to ensure our survival. Indeed the world has many stories of mass 
human migrations being triggered when either the engineering systems or the resilience failed.

Our goal for the future is to change that: to eliminate the threat that our livelihood and our lives will be disrupted by scarcity. This requires a different approach. "Engineered Solutions" must give way to "Collaborative Solutions" that combine infrastructure, incentives and information to effect change.

Such a change - recognizing the value of infrastructure and information in the delivery of water - can significantly increase our own resilience, and insulate society from a future of water austerity. But it is not simply a hydrologic solution we need. We need to consider how that water is delivered, how much water is delivered and how to manage our use such that we can achieve sustainability. These are institutional changes. The practices of the past cannot be the practices of the future.

We need to establish new mechanisms and policies for infrastructure, new methodologies to encourage conservation and strong pricing signals to ensure water, as a commodity, is treated with the respect and due care needed to ensure sustainability. And we have been afforded the opportunity to do so.

\section{Opportunity}

"The world today faces the enormous, dual challenges of renewing its decaying water infrastructure and building new water infrastructure. Now is an opportune moment to update the analytic strategies used for planning such grand investments under an uncertain and changing climate" [2].

The developed world has been presented with a unique opportunity: much of the world's first generation water and wastewater systems is at its end of life. We must take the opportunity not simply to perpetuate the Victorian model of water delivery, but instead configure our infrastructure and information systems for the $21^{\text {st }}$ century and beyond. This includes developing a "right water for the right use" philosophy as well as configuring our data systems to work as conduits of behavioural change.

\section{Infrastructure}

"In the 20th century we built this water system and it brings incredibly high quality potable water to our homes, and we use it to drink and to flush our toilets and to water our lawns. It's a crazy use of a wonderful resource" [3].

From the perspective of efficiency and conservation, the design of water distribution systems is inherently flawed. By providing only one piped source of water for use, communities are locked into a model in which all water must be treated to potable standards; all water must be maintained at a suitable pressure 
for instantaneous use; and new water must be found and accessed for each new person.

The limitation of this infrastructure model is revealed when one considers that the majority of water provided to customers is not consumed. Rather, it is used as outside irrigation, or as a means of transporting waste away from homes, or in other non-consumptive tasks. Depending on location, $44 \%$ of water is used outside the home. Inside the home, most of the water is used for nonconsumptive tasks. Toilet use represents $25 \%$ of the total water demand for a residence. These are ideal applications for recycled water and represent an opportunity to replace $59 \%$ of the water consumption with a non-potable supply (figure 1).

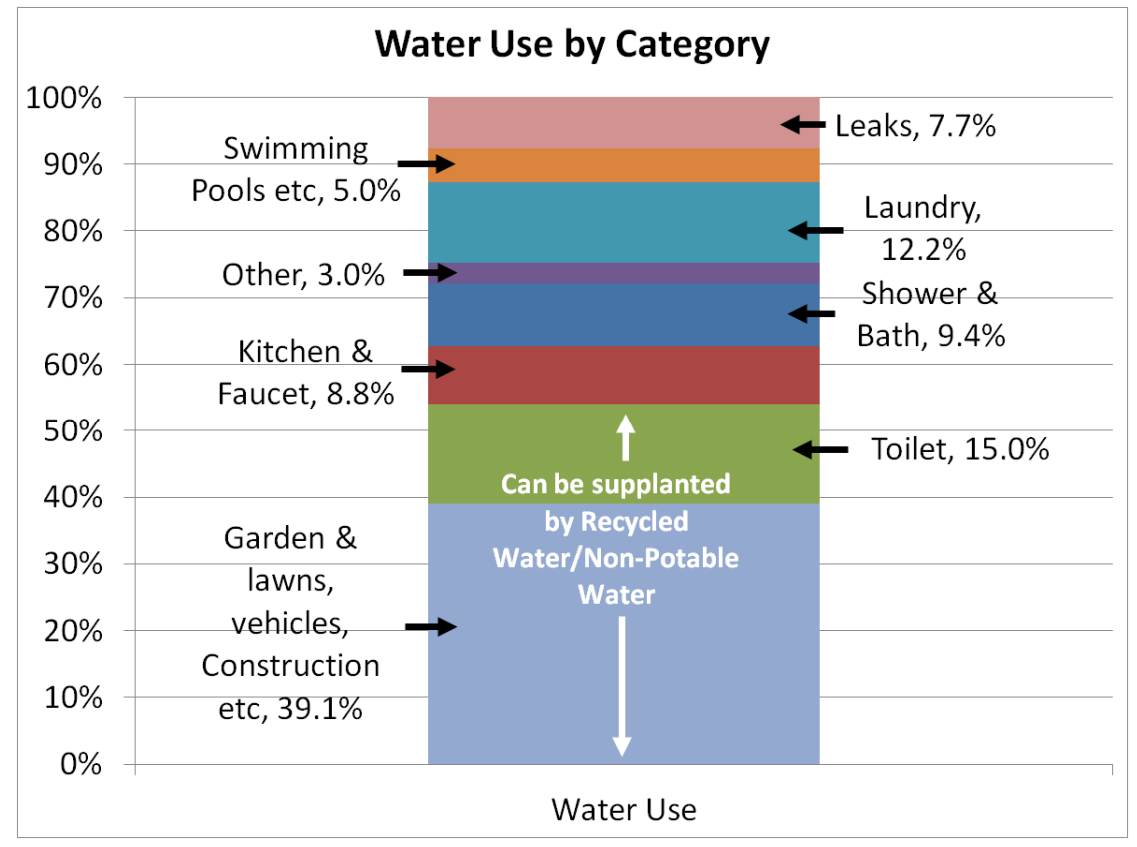

Figure 1: $\quad$ Water use by category [4].

\subsection{Water delivery schemes}

The delivery of water services can be separated into three broad categories:

- Systems in which there is no recycling;

- Systems which use recycled water for outside irrigation demands; and

- Systems which integrate recycled water for delivery inside residential dwelling units as a means of offsetting potable water consumption for non-potable uses. 
The Non-Recycling Configuration represents the standard water delivery methodology and employs potable water for all uses in a single-plumbed community. In this case, all water used in the community must be treated to potable water standards and new water must be found for each additional unit. Treated wastewater is discharged to the receiving environment without re-use.

The Basic Recycling configuration represents the use of recycled water for irrigation of common areas, Homeowners' Association open spaces, community amenities and schoolyards etc. In this configuration a water savings of $40 \%$ is possible.

In Advanced Recycling, recycled water is deployed through a dual-plumbed, highly distributed network allowing for the delivery of recycled water for the best and highest uses possible. This allows for all non-potable uses to be supplied by non-potable water resulting in up to a $60 \%$ reduction in potable water consumption.

The potential water savings are shown in figure 2 .

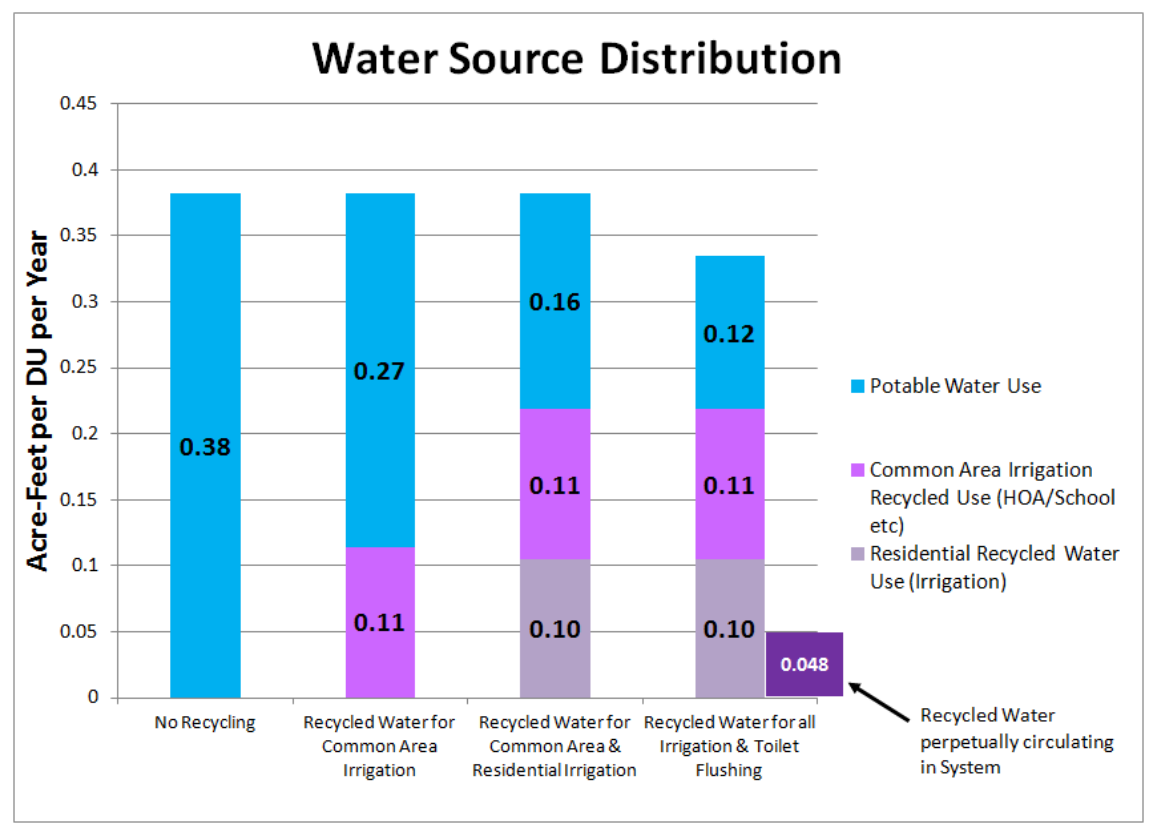

Figure 2: Comparison of water use under different water supply configurations.

Indeed these theoretical numbers (figure 2) are those being achieved at Global Water-Santa Cruz Water Company. In 2005, prior to the implementation of a recycled water plan, Global Water-Santa Cruz's overall consumption of potable 
water per connection customer was 12,286 gallons per month $\left(46.5 \mathrm{~m}^{3} / \mathrm{month}\right.$, or 0.45 acre-feet per year, AFY). In 2007, as recycled water infrastructure advanced, Global Water-Santa Cruz connections used 0.24 AFY of potable water and $0.13 \mathrm{AFY}$ of recycled water [5].

\section{Information}

"People don't recognize how powerful the pull of the crowd is on them... We can move people to environmentally friendly behaviour by simply telling them what those around them are doing" [6].

Infrastructure can only go so far. The economic value of water and the consumer's experiential understanding of where, when and how they consume water stands in the way of a sustainable future. There is simply not enough information available to generate the real-time behavioural changes necessary to reduce consumption. To change that requires utilities to adopt a highly focused and inclusive data sharing model.

While other industries have increased the speed, volume, availability and interoperability of data in order to maximize efficiencies, many water and wastewater utilities continue to manage water use based on singular, isolated data points.

Even in advanced utilities, customer information systems (CIS), supervisory control and data acquisition systems (SCADA), billing platforms, asset management systems, geo-spatial information systems (GIS) are often separate, managed by different departments, employed for specific tasks, and incapable of easily sharing data. The interoperability of these systems is compounded by the fact that the granularity of the data can differ by orders of magnitude. SCADA data is available at millisecond intervals; consumer consumption data is available at monthly intervals. This time-scale disparity complicates the ability to effectively use the data.

These disparate systems have resulted in "data insulation" - where potentially important relationships are unnoticed. For instance, rarely will the Billing Manager access SCADA data. And to the Operations Manager, monthly consumption data supplied 10 days after collection provides no basis from which to make decisions. SCADA systems lack the geo-spatial specificity used by the GIS Manager. And for the consumer, there is a total lack of real-time data.

In Global Water's case, we have developed FATHOM ${ }^{\mathrm{TM}}$ - an integrated suite of technologies that combines automated metering infrastructure (AMI) data, geographic information system data and customer information system data to produce information that the utility and the consumer can use to alter water consumption behaviour (figure 3).

In combination with traditional messaging and pricing, this increase in data availability has a dramatic impact on water use. 


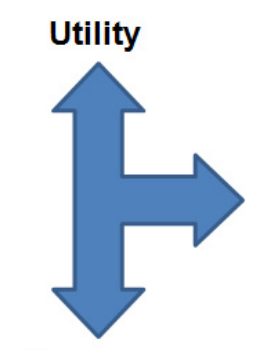

Consumers

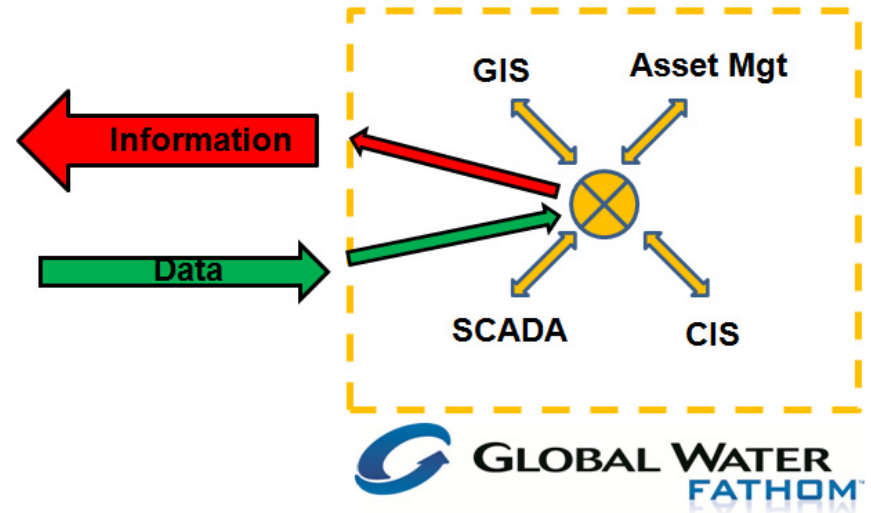

Figure 3: Global water FATHOM data model.

\subsection{Messaging}

Water conservation has been a major theme of most utilities. Websites and utility customer care centres are replete with exhortations to turn off the tap while brushing your teeth, to stop irrigating your lawn in the rain, to not use your hose as a brush for your driveway. These messages are important but often fall short of measurable impact. Water managers have been so successful in engineering solutions to our water needs that the average consumer not only believes that clean and plentiful water must be available on demand, but they pass not a thought about the complexity of this service. The ignorance of the personal impact each consumer has on our water resources is a major hurdle to sustainability.

Global's view is that the volatility of water resources in the face of an increasingly erratic climate system is rapidly driving our past engineeringcentred water management polices into obsolescence. To be sustainable, we need to adopt a distributed approach to the demand management - and that means engaging the consumer at a fundamentally more granular level.

\subsection{Data granularity}

A utility can tell you to the millisecond when a booster pump turned on; however, in many cases it cannot tell you until next month - or the month after, or six months later, or worse: never - where that water went. That's not acceptable. In a world where every drop counts, instantaneous understanding of the entire water system is required.

Further, in a time of shrinking population bases and dwindling budgets, continuity of revenue is now a major concern for utilities. And for consumers, that means costs are going up.

American Water Intelligence reports that water and wastewater rates increased an average of $8.1 \%$ between July 2010 and July 2011 [7]. Increasing price certainly makes people more aware of their usage. In 2009, Boenning and 
Scattergood noted: "as with the sudden interest in fuel-efficient cars in the U.S., consumers generally become much more interested in conservation and efficiency when the price of the commodity in question - be it oil or water becomes high enough to provide that motivation" [8].

In other words, when water is cheap, no one notices. As prices increase, people look to control their consumption. To do so requires data - data that most utilities cannot readily supply. However, given access to highly granular, timerelevant data, consumers can make dramatic changes in consumption. A recent study completed by California State University indicated that through the provision of instantaneous feedback on water consumption, average water consumption reductions in the order of $14 \%$ can be achieved [9]. Further, subtle societal pressures can be reinforced with access to such data.

The consumer needs to have the opportunity to review daily consumption, and make an economic decision based on that information. To be successful in reducing consumption, people must be given the "geo-temporal" context of their consumption: where, when and why am I using water.

By employing such a system, the consumer is afforded the opportunity to pause, and ask the questions: "Do I need to use that gallon of water?" and "Am I prepared to incur the costs of using that next gallon of water?"

The need for data to make decisions is a well worn business mantra. But it also applies to consumers. Jesse Berst recently opined "consumers want highly personalized information and they want it at any time on any device - Web, TV, print, smart phone" [10].

It is for this reason that the information presentment options are converging to mobile devices like Global Water FATHOM's iPhone application (figure 4).

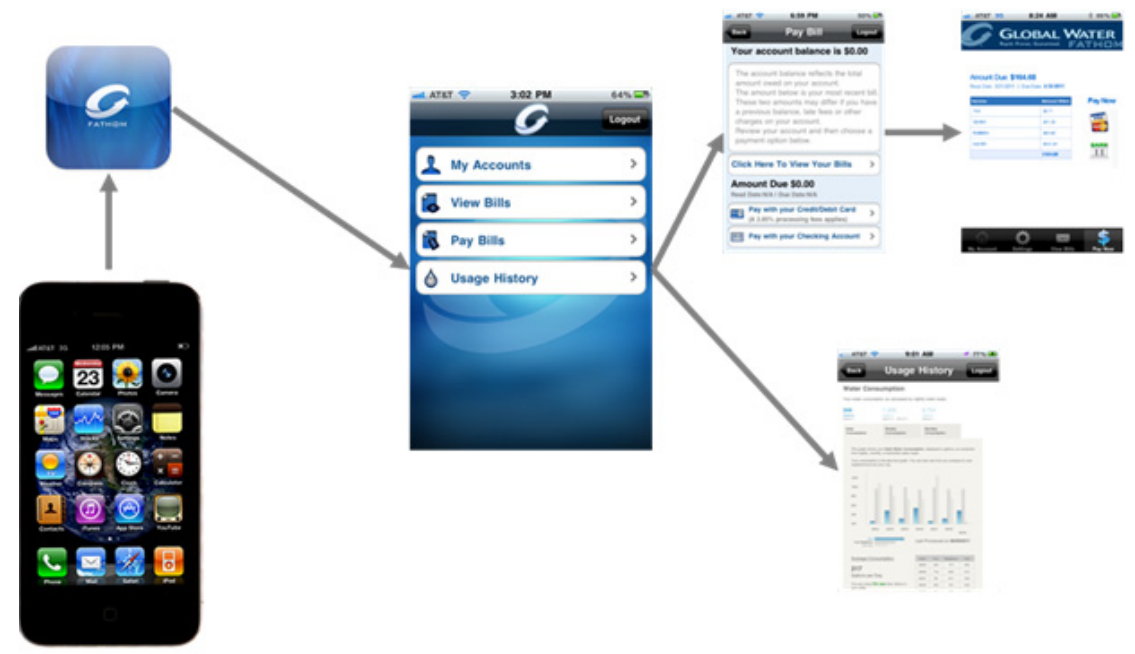

Figure 4: Global Water FATHOM consumer data access platform. 
This application is one of the first commercially available water conservation/consumption data delivery tools for consumers, and allows FATHOM utility customers to access near-real-time consumption data and billing information.

\title{
4.3 Pricing
}

"Rate design offers the double anti-oxymoron: price increases are consumer protection, because price increases change behaviour and behaviour change yields lower total costs" [11].

No talk about conservation can exist without an effective pricing mechanism. If water does not have real monetary value, consumers will not conserve.

On average, a $10 \%$ increase in the marginal cost of water can be expected to reduce residential demand by $3-4 \%$ in the short run. In the long term, such an increase could be expected to yield a $6 \%$ decrease in demand [12].

Clearly, price sensitivity to water resulting in demand reductions will reduce utility revenue. A true conservation-oriented rate structure must take into account this revenue destruction that is concomitant with demand reduction. Equally important, however, is that in order to mitigate revenue shortfalls, the utility must actively measure all water and monetize each drop. Eliminating non-revenue water is a critical element of the $21^{\text {st }}$ century utility.

\section{Results}

Infrastructure configuration has reduced potable water demand in Global utilities by a factor of two. By applying appropriate pricing signals and information we have seen a further average sustained reduction in demand of $16 \%$. Where we have deployed the FATHOM operating system, the impact of increased accuracy and water accounting has resulted in significant increases in the volume of water registered by each meter for billing (in one case of a utility with 2400 meters, an increase of 6.95 million gallons was measured for the first billing cycle - a $24.6 \%$ increase, resulting in a "found revenue" in the order of $\$ 11,500$ per month [13].

\section{Conclusions}

\author{
"Truly sustainable water management and use requires \\ efficiency, smart economics, advanced technology and better \\ governance and water management" [14].
}

The world of water resources management is changing rapidly - scarcity and price increases are a certainty. To adapt utilities must seek to increase sustainability through diversifying their water delivery paradigms - using the right water for the right use - as well as increasing the availability of data for consumers. For the first time in recent history, we have the opportunity to 
improve our water delivery systems. We have the ability to monitor and immediately report water use, dramatically increasing the visibility of water, and actively engage the end consumer in "direct-drive conservation": the real-time, conscious reduction in consumption. These are the necessary tools for our managed solution to water scarcity.

When combined with the right economics, dramatic and sustainable reductions in demand can be achieved. And our natural resources sustained for the future.

\section{References}

[1] P. Gleick, Roadmap for sustainable water resources in southwestern North America, PNAS, December 14, 2010.

[2] P. Milly, et al, "Stationarity is Dead: Whither Water Management?", Science, February 1, 2008.

[3] P. Gleick, Fresh Air, WHYY, November 27, 2007.

[4] Data compiled from Global Water data and USEPA, 2011 (http://www.epa.gov/WaterSense/pubs/indoor.html, http:/www.epa.gov/WaterSense/pubs/outdoor.html).

[5] Global Water - Santa Cruz Water Company data from Annual Reports filed with the Arizona Department of Water Resources.

[6] S. Simon, "The Secret to Turning Consumers Green", Wall Street Journal, October 18, 2010.

[7] American Water Intelligence, "Tariff Survey: Cities hike water charges as financing options evaporate", September 2011

[8] Boenning \& Scattergood, "Water Industry Review: M\&A Market Outlook", 2009.

[9] W. Schultz, W. DeCianni and A. Roldan, "Water Conservation Pilot", California State University, San Marcos, 2009 (http://www.kysq.org /docs/Aquacue.pdf)

[10] J. Berst, "The six things utilities still don't get about consumers (but better learn fast!)", Smart Grid News, April 5, 2011.

[11] S. Hempling, "Low Rates, High Rates, Wrong Rates, Right Rates", National Regulatory Research Institute, 2009.

[12] S. Olmstead, R. Stavins, "Comparing price and nonprice approaches to urban water conservation”, Water Resources Research, 45, W04301.

[13] Data derived from installation of FATHOM smart grid suite of technologies, 2011 (Global Water FATHOM).

[14] P. Gleick, "The Real Cost of Water We Use", presented at the Stanford Graduate School of Business, February 9, 2010. 